\title{
Induced autopolyploidy - a promising approach for enhanced biosynthesis of plant secondary metabolites: an insight
}

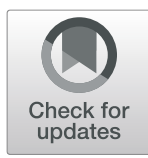

\author{
Saikat Gantait ${ }^{* \dagger}$ (D) and Eashan Mukherjee ${ }^{\dagger}$
}

\begin{abstract}
Background: Induced polyploidy serves as an efficient approach in extricating genetic potential of cells. During polyploidization, multiple sets of chromosomes are derived from the same organism resulting in the development of an autopolyploid. Alterations owing to artificially induced polyploidy level significantly influence internal homeostatic condition of resultant cells.

Main text: Induced autopolyploidy transpires as a result of an increase in the size of genome without any change in elementary genetic material. Such autopolyploidy, artificially induced via application of antimitotic agents, brings about a lot of beneficial changes in plants, coupled with very few detrimental effects. Induced autopolyploids exhibit superior adaptability, endurance to biotic and abiotic stresses, longer reproductive period and enzyme diversity coupled with enhanced rate of photosynthesis and gene action in comparison to their diploid counterparts. However, reduced rate of transpiration and growth, delay in flowering are some of the demerits of autopolyploids. Inspite of these slight unfavourable outcomes, induced autopolyploidization has been utilized in an array of instances wherein genetic improvement of plant species is concerned, since this technique usually boosts the biomass of concerned economic parts of a plant. In other way, it is also evident that multiplication of genome bestows enhanced production of secondary metabolites, which has contributed to a significant commercial value addition especially for plants with medicinal importance, in particular.
\end{abstract}

Conclusion: This review makes an attempt to explore the system and success of antimitotic agents vis-à-vis artificial autopolyploidization, interfered with the biosynthesis-cum-production of secondary metabolites having cutting-edge pharmaceutical importance.

Keywords: Antimitotic agents, Autotetraploid, Biosynthetic pathway, Colchicine, Oryzalin

\section{Background}

Induced polyploidy serves as an effective tool in extricating a cell's genetic potential. During polyploidization, when multiple sets of chromosomes are derived from the same organism, it results into the development of autopolyploidy. Induced multiple ploidy level affects a cell's internal homeostatic condition. This may lead to meiotic instabilities, undesirably magnified linkage

\footnotetext{
* Correspondence: saikatgantait@yahoo.com

'Saikat Gantait and Eashan Mukherjee contributed equally to this work. Crop Research Unit (Genetics and Plant Breeding), Bidhan Chandra Krishi Viswavidyalaya, Mohanpur, Nadia, West Bengal 741252, India
}

effects, chimeral tissues [1], poor sexual reproduction and other epigenetic changes in plants. Such aberrational problems are often associated with triploids and mixoploids whereby there persists a problem to pair chromosomes during meiosis. Despite these encumbrances, induced polyploidy provides several mileages in crop research and improvement. Firstly, duplication of the same genomic constituents produces genetically true-to-type individuals [2]. Genome re-duplication characterizes increased plant vigour and productivity through improved cellular activity status increasing cell size, stomatal size and number, nuclear size and activity $[2,3]$, gene

\section{Springer Open}

(๑) The Author(s). 2021 Open Access This article is licensed under a Creative Commons Attribution 4.0 International License, which permits use, sharing, adaptation, distribution and reproduction in any medium or format, as long as you give appropriate credit to the original author(s) and the source, provide a link to the Creative Commons licence, and indicate if changes were made. The images or other third party material in this article are included in the article's Creative Commons licence, unless indicated otherwise in a credit line to the material. If material is not included in the article's Creative Commons licence and your intended use is not permitted by statutory regulation or exceeds the permitted use, you will need to obtain permission directly from the copyright holder. To view a copy of this licence, visit http://creativecommons.org/licenses/by/4.0/. 
interaction and expression, transcriptome output, coordinated post-translational gene regulation resulting in increased metabolism, and henceforth higher production of alkaloids, flavones, phenolics, collectively the secondary metabolites $[4,5]$. As a consequence, both the quality and quantity of the secondary metabolite production receives a massive boost [6]. Such improvement could be obtained in proportionate terms across triploids, tetraploids and at other higher ploidy levels due to underlying multiple genetic dose effects [7]. However, such manipulative changes are also subject to genotype specificities.

Even though two review articles were published most recently on artificial polyploidization of medicinal and aromatic plants $[5,6]$, yet neither of them emphasized on the enhancement of secondary metabolite production precisely; in spite of the fact that genetic improvement of medicinal and aromatic plants focuses chiefly on quantitative development of essential oils and secondary metabolites.

Nearly about three decades earlier, the utility of induced polyploids for enhancing the productivity of secondary metabolites was highlighted [8]. Yet, it took more than 15 years to commence the all-encompassing usage of this technology, wherein starting from 2011 to 2020 , more than 60 research articles have been published focusing primarily on the use of antimitotic agents (e.g. colchicine, oryzalin and/or trifluralin, etc.) in order to multiply the ploidy level for attainment of elevated production of secondary metabolites (Table 1). Meanwhile, to the best of our knowledge, merely six results were reported on this concerned research topic in those 15 years (commencing from 1996 to 2010) [73-78]. It is noteworthy to mention that an array $(\sim 100)$ of successful attempts were reported $[5,6]$ on induction of polyploidy in medicinal and aromatic plants; however, $\sim 62$ of such reports were related to elevation of secondary metabolites production only.

\section{Main text}

\section{In vitro autopolyploidization}

The general procedure of in vitro autopolyploidisation involves initial treatment of the explants with a suitable antimitotic agent followed by shaking the treated explants on an orbital shaker, before being inoculated into culture media. As an alternative approach, antimitotic agents could directly be added to the basal media containing the inoculated explants for possible polyploidization, although the earlier process is more effective and less time taking. Subsequent culture, growth, acclimatization and morphological assessment, along with confirmation of chromosome doubling through flow cytometry and chromosome counting, are performed accordingly (Fig. 1). The various factors affecting successful in vitro polyploidization are discussed in the following sections.

\section{Influence of treatment condition}

Treatment conditions determine the final outcome of the experiment as they affect the endogenous metabolic processes leading to the upregulation or downregulation of the biochemical production. In most of the experiments, the explants were dipped, soaked or immersed into the polyploidy inducing solution resulting in imbibition of the chemicals. Colchicine, a polyploidy inducer, was applied after dissolving the same in dimethyl sulfoxide (DMSO) solution. Xing et al. [9] documented the enhanced effectiveness of colchicine dissolved in ethanol. The purpose of this was to increase the permeability of antimitotic agent(s) facilitating their entry into the regenerative tissues of the plant parts. As low as $2 \%(\mathrm{v} / \mathrm{v})$ DMSO was most commonly used (Table 1). Similarly, oryzalin was reported to be dissolved in ethanol [55] or DMSO (1\%) [62]. Exposure condition of the explants to antimitotic chemicals was recorded to differ across various publications. 'Cotton ball or plug method' for colchicine treatment was followed in several of the experiments (Table 1). Other experimental investigations state the addition of colchicine into the Murashige and Skoog (MS) basal medium [72] alone or in supplementation with plant growth regulators (PGRs), like $\alpha$-naphthalene acetic acid (NAA), $\mathrm{N}^{6}$-benzyladenine (BA) or thidiazuron (TDZ). Inoculation in liquid MS basal media (MSL) supplemented with colchicine were also reported (Table 1). In addition, it was found in some reports that inoculation was carried out by means of constant shaking, using an orbital shaker. In most of the cases, shaking was done at $100 \mathrm{rpm}$. Presumably, use of liquid basal media supplemented with orbital shaking increased the absorption of antimitotic agents by further increasing the per unit surface area exposure over time. However, such prolonged durations may harm young explants for instance delicate meristematic meristems, which can be avoided with the aid of the most effective chemical-soaked cotton plugging method. Dark conditions during the colchicine inoculation period were adopted in several investigations (Table 1). Such shock treatment imposed on explants undergoing high cell division (callus, seed) promotes redifferentiative meristematic activity and germination and in process exposure to polyploidy inducers. Outstandingly, high temperature treatments resulting in the development of $2 \mathrm{n}$ female gametes for production of triploids was carried out in Eucommia sp. [53]. Increased temperature interferes with spindle formation and affects chromosome multiplication during the process.

\section{Influence of plant part(s)/explant}

Appropriate selections of explants are imperative for effective polyploidization. The basic idea is that the explants must provide maximum conversion (polypoid cells) upon treatment that in turn would lead to generation of stable, high phytochemical yielding autopolyploid lines. Hence, 
Table 1 Antimitotic agent(s) and their influence on autopolyploidization and subsequent secondary metabolites production (arranged in chronological order)

\begin{tabular}{|c|c|c|c|c|c|c|}
\hline Plant spp. & Treatment condition & $\begin{array}{l}\text { Treated } \\
\text { plant part }\end{array}$ & $\begin{array}{l}\text { Type, dosage } \\
\text { and exposure } \\
\text { duration of } \\
\text { antimitotic } \\
\text { agent(s) }\end{array}$ & $\begin{array}{l}\text { Resultant ploidy } \\
\text { level }\end{array}$ & $\begin{array}{l}\text { Effect on secondary metabolite } \\
\text { production }\end{array}$ & Reference \\
\hline $\begin{array}{l}\text { Catharanthus } \\
\text { roseus Don. }\end{array}$ & $\begin{array}{l}\text { Immersed in colchicine } \\
\text { (dissolved in ethanol) soln. }\end{array}$ & Seed & $\begin{array}{l}\text { Colchicine; } \\
0.2 \% ; 24 \mathrm{~h}\end{array}$ & $\begin{array}{l}\text { Diploid } \rightarrow \text { Tetraploid } \\
(2 \mathrm{n}=4 \mathrm{x}=32)\end{array}$ & $\begin{array}{l}\text { Increase in terpenoid indole alkaloids } \\
(2-3 \text {-fold })\end{array}$ & [9] \\
\hline $\begin{array}{l}\text { Centella asiatica } \\
\text { (L.) }\end{array}$ & Soaked in colchicine solution & Shoot tip & $\begin{array}{l}\text { Colchicine; } \\
0.050-0.200 \% \\
12-24 \text { h }\end{array}$ & $\begin{array}{l}\text { Diploid } \rightarrow \text { Tetraploid } \\
(2 \mathrm{n}=4 \mathrm{x}=36)\end{array}$ & $\begin{array}{l}\text { Non-significant increase of } 11 \% \text { in } \\
\text { total triterpenes production }\end{array}$ & {$[10]$} \\
\hline $\begin{array}{l}\text { Catharanthus } \\
\text { roseus }\end{array}$ & NM & $\begin{array}{l}\text { Shooty } \\
\text { teratoma }\end{array}$ & $\begin{array}{l}\text { Colchicine: } \\
0.01 \% ; 24-48 \text { h }\end{array}$ & $\begin{array}{l}\text { Diploid } \rightarrow \text { Tetraploid } \\
(2 n=4 x=32)\end{array}$ & $\begin{array}{l}2 \text {-fold increment in vincristine } \\
\text { production }\end{array}$ & {$[11]$} \\
\hline $\begin{array}{l}\text { Solanum } \\
\text { commersonii }\end{array}$ & $\begin{array}{l}\text { Dipped in sterile and agitated } \\
\text { (100 rpm at r.t.) } \mathrm{H}_{2} \mathrm{O} \\
\text { containing oryzalin ( } 40 \mathrm{mg} / \mathrm{l} \\
\text { dissolved in } 1 \mathrm{ml} \text { of DMSO) }\end{array}$ & Shoot tip & $\begin{array}{l}\text { Oryzalin; } 10 \mathrm{mg} \\
\text { /l; } 24 \mathrm{~h}\end{array}$ & $\begin{array}{l}\text { Diploid } \rightarrow \text { Tetraploid } \\
(2 n=4 x=48)\end{array}$ & $\begin{array}{l}\text { Higher phenylpropanoid content } \\
\text { (approx. 2-fold) }\end{array}$ & {$[12]$} \\
\hline $\begin{array}{l}\text { Solanum } \\
\text { bulbocastanum }\end{array}$ & $\begin{array}{l}\text { Dipped in sterile and agitated } \\
\text { (100 rpm at r.t.) } \mathrm{H}_{2} \mathrm{O} \\
\text { containing oryzalin ( } 40 \mathrm{mg} / \mathrm{l} \\
\text { dissolved in } 1 \mathrm{ml} \text { of DMSO) }\end{array}$ & Shoot tip & $\begin{array}{l}\text { Oryzalin; } 10 \mathrm{mg} \\
\text { //; } 24 \mathrm{~h}\end{array}$ & $\begin{array}{l}\text { Diploid } \rightarrow \text { Tetraploid } \\
(2 n=4 x=48)\end{array}$ & $\begin{array}{l}\text { Similar or lower phenylpropanoids } \\
\text { and metabolites compared to } \\
\text { diploids }\end{array}$ & {$[13]$} \\
\hline $\begin{array}{l}\text { Rosa hybrida cv } \\
\text { lceberg }\end{array}$ & NM & NM & $\begin{array}{l}\text { Trifluralin; NM; } \\
\text { NM }\end{array}$ & $\begin{array}{l}\text { Triploid } \rightarrow \text { Hexaploid } \\
(2 n=6 x=42)\end{array}$ & Increase in phenolic compounds & {$[14]$} \\
\hline $\begin{array}{l}\text { Echinacea } \\
\text { purpurea (L.) }\end{array}$ & Colchicine soln. imbibition & Root tip & $\begin{array}{l}\text { Colchicine; } \\
0.25 \% ; 24-72 \mathrm{~h}\end{array}$ & $\begin{array}{l}\text { Diploid } \rightarrow \text { Tetraploid } \\
(2 \mathrm{n}=4 \mathrm{x}=44)\end{array}$ & $\begin{array}{l}\text { Increase in cichoric acid (45\%) and } \\
\text { chlorogenic acid (71\%) }\end{array}$ & {$[15]$} \\
\hline $\begin{array}{l}\text { Stevia } \\
\text { rebaudiana }\end{array}$ & $\begin{array}{l}\mathrm{H}_{2} \mathrm{O} \text { imbibed seed } \rightarrow \\
\text { colchicine (dissolved in 1\% } \\
\text { DMSO) soln. }\end{array}$ & Seed & $\begin{array}{l}\text { Colchicine; } \\
0.6 \% ; 24 \mathrm{~h}\end{array}$ & $\begin{array}{l}\text { Diploid } \rightarrow \text { Tetraploid } \\
(2 \mathrm{n}=4 \mathrm{x}=44)\end{array}$ & Increase in stevioside (approx. 2.4\%) & {$[16]$} \\
\hline $\begin{array}{l}\text { Cichorium } \\
\text { intybus L }\end{array}$ & $\begin{array}{l}\text { cotton covered meristem tip } \rightarrow \\
3 \text { droplets/treatment } \rightarrow 4 \text { times } \\
\text { at treatment intervals }\end{array}$ & $\begin{array}{l}\text { Shoot apical } \\
\text { meristem }\end{array}$ & $\begin{array}{l}\text { Colchicine; } \\
0.05 \% ; 8 \mathrm{~h}\end{array}$ & $\begin{array}{l}\text { Diploid } \rightarrow \text { Tetraploid } \\
(2 n=4 x=36)\end{array}$ & $\begin{array}{l}\text { 1.9-fold increase in total phenolic; } 10- \\
\text { fold increase in chlorogenic acid }\end{array}$ & {$[17]$} \\
\hline $\begin{array}{l}\text { Allium sativum } \\
\text { L. }\end{array}$ & $\begin{array}{l}\text { Soaked in basal media (liquid } \\
\text { B5 + } 2 \% \text { DMSO + colchicine) }\end{array}$ & Stem disc & $\begin{array}{l}\text { Colchicine; } \\
0.5 \% ; 36 \mathrm{~h}\end{array}$ & $\begin{array}{l}\text { Diploid } \rightarrow \text { tetraploid } \\
(2 n=4 x=32)\end{array}$ & Increase in allicin conc. (30.7\%) & {$[18]$} \\
\hline $\begin{array}{l}\text { Pfaffia } \\
\text { glomerata } \\
\text { (Spreng.) } \\
\text { Pedersen }\end{array}$ & Basal media + colchicine & Nodal bud & $\begin{array}{l}\text { Colchicine; } 30 \\
\mu \mathrm{M} ; 1 \mathrm{w}\end{array}$ & $\begin{array}{l}\text { Diploid } \rightarrow \text { tetraploid } \\
(2 n=4 x=68)\end{array}$ & $\begin{array}{l}\text { Increase in } \beta \text {-ecdysone production } \\
(50 \%)\end{array}$ & {$[19]$} \\
\hline $\begin{array}{l}\text { Dracocephalum } \\
\text { kotschyi Boiss }\end{array}$ & $\begin{array}{l}\text { Colchicine soln. } \rightarrow \text { cotton ball } \\
\text { method } \rightarrow \text { SAM ( } 2 \text { leaf and } 4 \\
\text { leaf stage) }\end{array}$ & $\begin{array}{l}\text { Shoot apical } \\
\text { meristem }\end{array}$ & $\begin{array}{l}\text { Colchicine; } \\
0.5 \% ; 48 \mathrm{~h}\end{array}$ & $\begin{array}{l}\text { Diploid } \rightarrow \text { tetraploid } \\
(2 n=4 x=40)\end{array}$ & $\begin{array}{l}\text { Increase in methoxylated } \\
\text { hydroxyflavones (approx. 19.41\%) }\end{array}$ & {$[20]$} \\
\hline $\begin{array}{l}\text { Centella asiatica } \\
\text { (L.) }\end{array}$ & Soaked in colchicine solution & Shoot tip & $\begin{array}{l}\text { Colchicine; } \\
0.050-0.200 \% \\
12-24 \text { h }\end{array}$ & $\begin{array}{l}\text { Diploid } \rightarrow \text { Tetraploid } \\
(2 n=4 x=36)\end{array}$ & $\begin{array}{l}\text { Increase in total triterpenoid (approx. } \\
30.5 \% \text { ) }\end{array}$ & {$[21]$} \\
\hline $\begin{array}{l}\text { Echinacea } \\
\text { purpurea (L.) } \\
\text { Moench }\end{array}$ & $\begin{array}{l}\text { Shoot regeneration media }+ \\
\text { colchicine }\end{array}$ & Petiole & $\begin{array}{l}\text { Colchicine; } 30- \\
240 \mathrm{mg} / \mathrm{l} \text { for } 30 \\
\mathrm{~d} \text { or } 120 \mathrm{mg} / \mathrm{l} \\
\text { for } 7,14,21 \text { or } \\
28 \mathrm{~d}\end{array}$ & $\begin{array}{l}\text { Diploid } \rightarrow \text { tetraploid } \\
(2 n=4 x=44)\end{array}$ & Increase in caffeic acid and alkamides & {$[22]$} \\
\hline Nigella sativa $\mathrm{L}$. & $\begin{array}{l}\text { Colchicine (dissolved in } 2 \% \\
\text { DMSO) soln. treatment }\end{array}$ & Seed & $\begin{array}{l}\text { Colchicine; } \\
0.05 \% ; 4 \mathrm{~h}\end{array}$ & $\begin{array}{l}\text { Diploid } \rightarrow \text { tetraploid } \\
(2 n=4 x=24)\end{array}$ & $\begin{array}{l}\text { Increase in thymoquinone conc. } \\
(46.3 \%)\end{array}$ & {$[23]$} \\
\hline \multirow{2}{*}{$\begin{array}{l}\text { Stevia } \\
\text { rebaudiana } \\
\text { Bertoni }\end{array}$} & \multirow[t]{2}{*}{ NM } & \multirow[t]{2}{*}{ NM } & \multirow[t]{2}{*}{$\begin{array}{l}\text { Colchicine; NM; } \\
\text { NM }\end{array}$} & $\begin{array}{l}\text { Diploid } \rightarrow \text { tetraploid } \\
(2 n=4 x=44)\end{array}$ & $\begin{array}{l}\text { Increase in rebaudioside-A (6.21\%) in } \\
\text { tetraploid; }\end{array}$ & {$[24]$} \\
\hline & & & & $\begin{array}{l}\text { Triploids and } \\
\text { mixoploids }\end{array}$ & Increase in (13.50\%) stevioside & \\
\hline Thymus persicus & $\begin{array}{l}\text { Immersed in colchicine soln. } \\
\text { (dissolved in } 2 \% \text { DMSO) } \rightarrow \\
\text { sterile } \mathrm{H}_{2} \mathrm{O} \text { washing }\end{array}$ & Shoot tip & $\begin{array}{l}\text { Colchicine; } \\
0.3 \% ; 12 \mathrm{~h}\end{array}$ & $\begin{array}{l}\text { Diploid } \rightarrow \text { tetraploid } \\
(2 n=4 x=56)\end{array}$ & $\begin{array}{l}\text { Increase in betulinic acid }(69.73 \%) \text {, } \\
\text { oleanolic acid }(42.76 \%), \text { ursolic acid } \\
(140.67 \%)\end{array}$ & {$[25]$} \\
\hline \multirow{2}{*}{$\begin{array}{l}\text { Stevia } \\
\text { rebaudiana } \\
\text { Bertoni }\end{array}$} & \multirow[t]{2}{*}{ Treatment in field condition } & \multirow[t]{2}{*}{ NM } & $\begin{array}{l}\text { Colchicine; } \\
2.5 \% \text {; NM }\end{array}$ & $\begin{array}{l}\text { Diploid } \rightarrow \text { tetraploid } \\
(2 n=4 x=44)\end{array}$ & Increase in rebaudioside-A (6.21\%) & \multirow[t]{2}{*}[26]{} \\
\hline & & & $\begin{array}{l}\text { Colchicine; } \\
1.50 \% ; \mathrm{NM}\end{array}$ & Mixoploid & Increase in steviosisde (13.50\%) & \\
\hline
\end{tabular}


Table 1 Antimitotic agent(s) and their influence on autopolyploidization and subsequent secondary metabolites production (arranged in chronological order) (Continued)

\begin{tabular}{|c|c|c|c|c|c|c|}
\hline Plant spp. & Treatment condition & $\begin{array}{l}\text { Treated } \\
\text { plant part }\end{array}$ & $\begin{array}{l}\text { Type, dosage } \\
\text { and exposure } \\
\text { duration of } \\
\text { antimitotic } \\
\text { agent(s) }\end{array}$ & $\begin{array}{l}\text { Resultant ploidy } \\
\text { level }\end{array}$ & $\begin{array}{l}\text { Effect on secondary metabolite } \\
\text { production }\end{array}$ & Reference \\
\hline $\begin{array}{l}\text { Tetradenia } \\
\text { riparia }\end{array}$ & Submerged in colchicine soln. & Seed & $\begin{array}{l}\text { Colchicine; } 0.01 \\
\mathrm{~g} / \mathrm{l} ; 24 \mathrm{~h}\end{array}$ & $\begin{array}{l}\text { Diploid } \rightarrow \text { tetraploid } \\
(2 n=4 x=)\end{array}$ & $\begin{array}{l}\text { Increase in essential oi production } \\
\text { (3.5-fold) }\end{array}$ & {$[27]$} \\
\hline $\begin{array}{l}\text { Echinacea } \\
\text { purpurea L. }\end{array}$ & $\begin{array}{l}\mathrm{MS}+0.4 \mathrm{mg} / \mathrm{l} \mathrm{BA}+0.01 \mathrm{mg} / \mathrm{l} \\
\mathrm{NAA}+\text { Colchicine }\end{array}$ & Petiole & $\begin{array}{l}\text { Colchicine; } 100 \\
\mathrm{mg} / \mathrm{l} ; 37 \mathrm{~d}\end{array}$ & $\begin{array}{l}\text { Diploid } \rightarrow \text { tetraploid } \\
(2 n=4 x=44) \\
\text { Tetraploid } \rightarrow \text { octaploid } \\
(2 n=8 x=88)\end{array}$ & $\begin{array}{l}\text { Increase in cichoric acid content in } \\
\text { octoploid (13.76 and } 29.84 \mathrm{mg} / \mathrm{g} \text { ) and } \\
\text { tetraploid (10.38 and } 22.32 \mathrm{mg} / \mathrm{g} \text { ) } \\
\text { than diploid plantlets ( } 8.21 \text { and } 18.42 \\
\text { mg/g) aboveground and } \\
\text { underground parts, respectively }\end{array}$ & {$[28]$} \\
\hline $\begin{array}{l}\text { Miscanthus } \times \\
\text { giganteus }\end{array}$ & NM & NM & $\begin{array}{l}\text { Colchicine; NM; } \\
\text { NM }\end{array}$ & $\begin{array}{l}\text { Triploid } \rightarrow \text { hexaploid } \\
(2 \mathrm{n}=6 \mathrm{x}=114)\end{array}$ & $\begin{array}{l}\text { Lower phenolic compounds in } \\
\text { hexaploids }(1266 \mu \mathrm{g} / \mathrm{g} \text { and } 1349 \mu \mathrm{g} / \\
\mathrm{g}) \text { than triploid }(1570 \mu \mathrm{g} / \mathrm{g} \text { and } 2268 \\
\mu \mathrm{g} / \mathrm{g})\end{array}$ & {$[29]$} \\
\hline $\begin{array}{l}\text { Lippia } \\
\text { integrifolia }\end{array}$ & $(\mathrm{MS}+2.2 \mu \mathrm{M} \mathrm{BA})+$ colchicine & $\begin{array}{l}\text { Nodal } \\
\text { segment }\end{array}$ & $\begin{array}{l}\text { Colchicine; } \\
0.01 \% ; 15 \mathrm{~d}\end{array}$ & $\begin{array}{l}\text { Diploid } \rightarrow \text { tetraploid } \\
(2 n=4 x=72)\end{array}$ & Increase in total monoterpene (9\%) & {$[30]$} \\
\hline $\begin{array}{l}\text { Pogostemon } \\
\text { cablin }\end{array}$ & $\begin{array}{l}\text { MSL }+ \text { colchicine } \rightarrow \text { shaking at } \\
100 \mathrm{rpm} \text { at } 25^{\circ} \mathrm{C}\end{array}$ & Cluster bud & $\begin{array}{l}\text { Colchicine; } \\
0.05 \% ; 72 \mathrm{~h}\end{array}$ & $\begin{array}{l}\text { Tetraploid } \rightarrow \text { octaploid } \\
(2 \mathrm{n}=8 \mathrm{x}=128)\end{array}$ & $\begin{array}{l}\text { Increase in patchoulic alcohol (2.6- } \\
\text { fold) }\end{array}$ & {$[31]$} \\
\hline $\begin{array}{l}\text { Chamaemelum } \\
\text { nobile L. }\end{array}$ & $\begin{array}{l}\mathrm{MSL}+1 \mu \mathrm{M} \text { NAA }+0.5 \mu \mathrm{M} \\
\mathrm{BAP}+\text { Colchicine; } 25^{\circ} \mathrm{C} \text {; Dark } \\
\text { for } 12 \mathrm{~h}\end{array}$ & Callus & $\begin{array}{l}\text { Colchicine; } \\
0.1 \% ; 12 \mathrm{~h}\end{array}$ & $\begin{array}{l}\text { Diploid } \rightarrow \text { tetraploid } \\
(2 n=4 x=36)\end{array}$ & Increase in essential oil (2-fold) & {$[32]$} \\
\hline $\begin{array}{l}\text { Bacopa } \\
\text { monnieri }\end{array}$ & $\begin{array}{l}\text { Treated with colchicine } \\
\text { (dissolved in 1\% DMSO) }\end{array}$ & Leaf & $\begin{array}{l}\text { Colchicine; } \\
0.1 \% ; 2 \mathrm{~h}\end{array}$ & $\begin{array}{l}\text { Diploid } \rightarrow \text { tetraploid } \\
(2 n=4 x=128)\end{array}$ & $\begin{array}{l}\text { Increase in bacoside (more than 4- } \\
\text { fold) }\end{array}$ & [33] \\
\hline \multirow[t]{3}{*}{$\begin{array}{l}\text { Capsicum } \\
\text { frutescens } L .\end{array}$} & \multirow{2}{*}{$\begin{array}{l}\text { Immersed in colchicine soln. } \\
\text { under dark condition; shaken } \\
\text { at } 100 \mathrm{rpm}\end{array}$} & \multirow[t]{3}{*}{ Seed } & $\begin{array}{l}\text { Colchicine; } 300 \\
\mathrm{mg} / \mathrm{l} ; 6 \mathrm{~h}\end{array}$ & $\begin{array}{l}\text { Diploid } \rightarrow \text { tetraploid } \\
(2 n=4 x=48)\end{array}$ & Increase in capsaicin (1.37-fold) & {$[34]$} \\
\hline & & & Oryzalin; 30 & & Increase in capsaicin (1.36-fold) & \\
\hline & $\begin{array}{l}\text { Immersed in oryzalin soln. } \\
\text { under dark condition shaken } \\
\text { at } 100 \mathrm{rpm}\end{array}$ & & mg/l; 6 h & & & \\
\hline $\begin{array}{l}\text { Aquilaria } \\
\text { malaccensis } \\
\text { Lamarck }\end{array}$ & NM & $\begin{array}{l}\text { Nodal } \\
\text { segment }\end{array}$ & $\begin{array}{l}\text { Trifluralin; } 0.1 \\
\mathrm{mM} ; 120 \mathrm{~h}\end{array}$ & $\begin{array}{l}\text { Diploid } \rightarrow \text { tetraploid } \\
(2 n=4 x=28)\end{array}$ & $\begin{array}{l}\text { Presence of sesquiterpene, a-guaiene } \\
(2.92 \%)\end{array}$ & {$[35]$} \\
\hline \multirow[t]{2}{*}{$\begin{array}{l}\text { Cannabis sativa } \\
\text { L. }\end{array}$} & \multirow[t]{2}{*}{$\begin{array}{l}\text { Through micropipette } \rightarrow 4 \\
\text { times at } 6 \mathrm{~h} \text { interval }\end{array}$} & \multirow[t]{2}{*}{$\begin{array}{l}\text { Apical } \\
\text { meristem }\end{array}$} & $\begin{array}{l}\text { Colchicine; } \\
0.2 \% ; 24 \mathrm{~h}\end{array}$ & $\begin{array}{l}\text { Diploid } \rightarrow \text { tetraploid } \\
(2 n=4 x=40)\end{array}$ & Increase in cannabinoid (1.2-fold) & \multirow[t]{2}{*}[36]{} \\
\hline & & & $\begin{array}{l}\text { Colchicine; } \\
0.1 \% ; 24 \mathrm{~h}\end{array}$ & Diploid $\rightarrow$ mixoploid & Increase in cannabinoid (1.6-fold) & \\
\hline $\begin{array}{l}\text { Anoectochilus } \\
\text { formosanus } \\
\text { Hayata }\end{array}$ & MSL + colchicine & Nodal stem & $\begin{array}{l}\text { Colchicine; } 100 \\
\mathrm{mg} / \mathrm{l} ; 3 \mathrm{~d}\end{array}$ & $\begin{array}{l}\text { Diploid } \rightarrow \text { tetraploid } \\
(2 n=4 x=48)\end{array}$ & $\begin{array}{l}\text { Increase in total flavonoid (0.5-fold) } \\
\text { and gastrodin ( } 4 \text {-fold) }\end{array}$ & {$[37]$} \\
\hline $\begin{array}{l}\text { Trachyspermum } \\
\text { ammi L. }\end{array}$ & $\begin{array}{l}\mathrm{MS}+\text { colchicine (Dissolved in } \\
\text { distilled } \mathrm{H}_{2} \mathrm{O}+2 \% \text { DMSO) }\end{array}$ & Seed & $\begin{array}{l}\text { Colchicine; } \\
0.05 \% ; 24 \mathrm{~h}\end{array}$ & $\begin{array}{l}\text { Diploid } \rightarrow \text { tetraploid } \\
(2 n=4 x=36)\end{array}$ & $\begin{array}{l}\text { Increase in thymol in tetraploid } \\
(69.2 \%) \text { over diploids }(49.67 \%)\end{array}$ & {$[38]$} \\
\hline Linum album & $\begin{array}{l}\mathrm{MS}+0.4 \mathrm{mg} / \mathrm{l} \mathrm{KIN}+ \\
\text { colchicine } \rightarrow \text { shaking at } 100 \\
\text { rpm }\end{array}$ & $\begin{array}{l}\text { Nodal } \\
\text { segment }\end{array}$ & $\begin{array}{l}\text { Colchicine; } 2.5 \\
\mathrm{mM} ; 72 \mathrm{~h}\end{array}$ & $\begin{array}{l}\text { Diploid } \rightarrow \text { tetraploid } \\
(2 n=4 x=60)\end{array}$ & $\begin{array}{l}\text { Increase in total phenolics ( } 1.8 \text {-and } \\
2.1 \text {-fold) and flavonoids (1.55- and } \\
1.53 \text {-fold) in regenerated stem and } \\
\text { leaf, respectively }\end{array}$ & [39] \\
\hline $\begin{array}{l}\text { Platycodon } \\
\text { grandiflorum }\end{array}$ & NM & Seedling & $\begin{array}{l}\text { Colchicine; NM; } \\
\text { NM }\end{array}$ & $\begin{array}{l}\text { Diploid } \rightarrow \text { tetraploid } \\
(2 n=4 x=36)\end{array}$ & Increase in metabolite content (NM) & {$[40]$} \\
\hline $\begin{array}{l}\text { Dendrobium } \\
\text { hybrids }\end{array}$ & $\begin{array}{l}\text { Suspension culture + } \\
\text { colchicine/ Amiprophos- } \\
\text { methyl }\end{array}$ & $\begin{array}{l}\text { Protocorm } \\
\text { like body }\end{array}$ & $\begin{array}{l}\text { Colchicine; } \\
0.050 \% ; 3 \mathrm{~d} \\
\text { Amiprophos- } \\
\text { methyl; } 2.5 \mu \mathrm{M} \text {; } \\
3 \mathrm{~d}\end{array}$ & $\begin{array}{l}\text { Diploid } \rightarrow \text { tetraploid } \\
(2 n=4 x=76)\end{array}$ & $\begin{array}{l}\text { Increase in shihundine and hircinol } \\
\text { (NM) }\end{array}$ & {$[41]$} \\
\hline $\begin{array}{l}\text { Sphagneticola } \\
\text { calendulacea } \\
\text { (L.) Pruski }\end{array}$ & $\begin{array}{l}\text { Incubation in MSL+ 2\% DMSO } \\
+ \text { Colchicine } \rightarrow \text { shaking }(100 \\
\text { rpm) at } 25^{\circ} \mathrm{C}\end{array}$ & Shoot tip & $\begin{array}{l}\text { Colchicine; } \\
0.05 \% ; 24 \mathrm{~h}\end{array}$ & $\begin{array}{l}\text { Diploid } \rightarrow \text { tetraploid } \\
(2 n=4 x=100)\end{array}$ & Increase in wedelolactone (1.66-fold) & {$[42]$} \\
\hline $\begin{array}{l}\text { Stevia } \\
\text { rebaudiana }\end{array}$ & $\begin{array}{l}\text { Imbibed in colchicine soln. } \\
\text { (dissolved in } 2 \% \text { DMSO) in }\end{array}$ & Seed & $\begin{array}{l}\text { Colchicine; } \\
.01 \% ; 24 \mathrm{~h}\end{array}$ & $\begin{array}{l}\text { Diploid } \rightarrow \text { tetraploid } \\
(2 n=4 x=44)\end{array}$ & $\begin{array}{l}\text { Increase in stevioside ( } 2.5 \text {-fold) and } \\
\text { rebaudioside- } A \text { ( } 1.5 \text {-fold })\end{array}$ & {$[43]$} \\
\hline
\end{tabular}


Table 1 Antimitotic agent(s) and their influence on autopolyploidization and subsequent secondary metabolites production (arranged in chronological order) (Continued)

\begin{tabular}{|c|c|c|c|c|c|c|}
\hline Plant spp. & Treatment condition & $\begin{array}{l}\text { Treated } \\
\text { plant part }\end{array}$ & $\begin{array}{l}\text { Type, dosage } \\
\text { and exposure } \\
\text { duration of } \\
\text { antimitotic } \\
\text { agent(s) }\end{array}$ & $\begin{array}{l}\text { Resultant ploidy } \\
\text { level }\end{array}$ & $\begin{array}{l}\text { Effect on secondary metabolite } \\
\text { production }\end{array}$ & Reference \\
\hline $\begin{array}{l}\text { Eclipta alba (L.) } \\
\text { Hassk }\end{array}$ & $\begin{array}{l}\text { MSL }+ \text { colchicine }+2 \% \\
\mathrm{DMSO} \rightarrow \text { shaking at } 100 \mathrm{rpm}\end{array}$ & Shoot tip & $\begin{array}{l}\text { Colchicine; } \\
0.1 \% ; 24 \mathrm{~h}\end{array}$ & $\begin{array}{l}\text { Diploid } \rightarrow \text { tetraploid } \\
(2 n=4 x=44)\end{array}$ & $\begin{array}{l}\text { Increase in wedelolactone (approx. 3- } \\
\text { fold) }\end{array}$ & {$[44]$} \\
\hline $\begin{array}{l}\text { Stevia } \\
\text { rebaudiana } \\
\text { Bertoni }\end{array}$ & $\begin{array}{l}\text { Cotton plug method } \rightarrow \\
\text { colchicine-soaked cotton } \\
\text { placed on bud }\end{array}$ & Axillary bud & $\begin{array}{l}\text { Colchicine; } \\
1.0 \% ; 3 \mathrm{~d}\end{array}$ & $\begin{array}{l}\text { Diploid } \rightarrow \text { tetraploid } \\
(2 n=4 x=44)\end{array}$ & Increase in stevioside (2.5-fold) & {$[45]$} \\
\hline $\begin{array}{l}\text { Sophora } \\
\text { tonkinensis } \\
\text { Gapnep }\end{array}$ & Immersed in colchicine soln. & $\begin{array}{l}\text { Adventitious } \\
\text { bud (from } \\
\text { epicotyl) }\end{array}$ & $\begin{array}{l}\text { Colchicine; } \\
0.2 \% ; 30 \mathrm{~h}\end{array}$ & $\begin{array}{l}\text { Diploid } \rightarrow \text { tetraploid } \\
(2 n=4 x=36)\end{array}$ & $\begin{array}{l}\text { Higher productivity of matrine and } \\
\text { oxymatrine }(1.31 \text {-fold })\end{array}$ & {$[46]$} \\
\hline $\begin{array}{l}\text { Andrographis } \\
\text { paniculata }\end{array}$ & $\begin{array}{l}\text { Soaked in colchicine soln at } 4 \\
\pm 1{ }^{\circ} \mathrm{C} \rightarrow \text { fresh colchicine soln. } \\
\text { at } 40 \pm 1^{\circ} \mathrm{C}\end{array}$ & Seed & $\begin{array}{l}\text { Colchicine; } \\
0.01 \% ; 40 \text { min \& } \\
20 \text { min }\end{array}$ & $\begin{array}{l}\text { Diploid } \rightarrow \text { tetraploid } \\
(2 \mathrm{n}=4 \mathrm{x}=100)\end{array}$ & Increase in andrographolide (28\%) & {$[47]$} \\
\hline $\begin{array}{l}\text { Salvia } \\
\text { miltiorrhiza }\end{array}$ & $\begin{array}{l}\mathrm{MS}+0.5 \mathrm{mg} / \mathrm{TDZ}+ \\
\text { colchicine }\end{array}$ & $\begin{array}{l}\text { Leaf } \\
\text { segment }\end{array}$ & $\begin{array}{l}\text { Colchicine; } 0.5 \\
\mathrm{mg} / \mathrm{l} ; 3 \mathrm{w}\end{array}$ & $\begin{array}{l}\text { Diploid } \rightarrow \text { tetraploid } \\
(2 n=4 x=32)\end{array}$ & $\begin{array}{l}\text { Increase in dihydrotanshinone and } \\
\text { total tanshinones (approx. 1.5-fold) }\end{array}$ & {$[48]$} \\
\hline $\begin{array}{l}\text { Bletilla striata } \\
\text { (Thunb.) Reichb. }\end{array}$ & $\begin{array}{l}\text { MSL + colchicine; dark at } 25 \pm \\
2{ }^{\circ} \mathrm{C}\end{array}$ & Seed & $\begin{array}{l}\text { Colchicine; } \\
0.1 \% ; 7 \mathrm{~d}\end{array}$ & $\begin{array}{l}\text { Diploid } \rightarrow \text { tetraploid } \\
(2 n=4 x=64)\end{array}$ & Increase in total phenolics (1.6 folds) & {$[49]$} \\
\hline $\begin{array}{l}\text { Andrographis } \\
\text { paniculata } \\
\text { (Burm. F.) wall. } \\
\text { ex Nees }\end{array}$ & NM & NM & $\begin{array}{l}\text { Colchicine; NM; } \\
\text { NM }\end{array}$ & $\begin{array}{l}\text { Diploid } \rightarrow \text { tetraploid } \\
(2 n=4 x=100)\end{array}$ & Increase in leaf metabolite (NM) & {$[50]$} \\
\hline $\begin{array}{l}\text { Stevia } \\
\text { rebaudiana } \\
\text { (Bertoni) }\end{array}$ & Inoculation in colchicine soln. & $\begin{array}{l}\text { Adventitious } \\
\text { bud }\end{array}$ & $\begin{array}{l}\text { Colchicine; } \\
0.20 \% ; 12 \mathrm{~h}\end{array}$ & $\begin{array}{l}\text { Diploid } \rightarrow \text { tetraploid } \\
(2 n=4 x=44)\end{array}$ & $\begin{array}{l}\text { Increase in steviol glycosides (approx. } \\
1.27 \text {-fold) }\end{array}$ & {$[51]$} \\
\hline $\begin{array}{l}\text { Datura } \\
\text { stramonium L. }\end{array}$ & Soaked in colchicine & Seed & $\begin{array}{l}\text { Colchicine; 1\%; } \\
48 \mathrm{~h}\end{array}$ & $\begin{array}{l}\text { Diploid } \rightarrow \text { tetraploid } \\
(2 n=4 x=48)\end{array}$ & Increase in alkaloids (7.25\%) & {$[52]$} \\
\hline Eucommia sp. & $\begin{array}{l}\text { High temperature induction of } \\
2 n \text { female parent } \rightarrow 2 n \text { female } \\
\text { gamete } \times \text { haploid pollen }\end{array}$ & Megaspore & $\begin{array}{l}\text { High } \\
\text { temperature; } \\
\text { NM; NM }\end{array}$ & $\begin{array}{l}\text { Diploid } \times \text { haploid } \rightarrow \\
\text { triploid }(3 n=51)\end{array}$ & $\begin{array}{l}\text { Increase in chlorogenic acid (10.20\%), } \\
\text { aucubin (1.34\%), geniposide } \\
(118.22 \%) \text {, geniposidic acid (22.04\%) }\end{array}$ & [53] \\
\hline $\begin{array}{l}\text { Bacopa } \\
\text { monnieri }\end{array}$ & $\begin{array}{l}\text { MSL + colchicine soln. } \rightarrow \\
\text { shaking }(100 \mathrm{rpm}) \text { at } 25 \pm 2^{\circ} \mathrm{C} \text {; } \\
10 \mathrm{~h} \mathrm{PP} ; 20 \mu \mathrm{mol} / \mathrm{m}^{2} \mathrm{LI}\end{array}$ & $\begin{array}{l}\text { Nodal } \\
\text { segment }\end{array}$ & $\begin{array}{l}\text { Colchicine; } \\
0.5 \% ; 48 \mathrm{~h}\end{array}$ & $\begin{array}{l}\text { Diploid } \rightarrow \text { tetraploid } \\
(2 n=4 x=128)\end{array}$ & Increase in bacoside (2.3-fold) & {$[54]$} \\
\hline Cannabis sativa & $\begin{array}{l}\text { Dipped in MSL + oryzalin } \\
\text { media ( } 37.5 \mathrm{mM} \text { oryzalin } \\
\text { dissolved in } 80 \% \text { ethanol) } \rightarrow \\
\text { tin foil cover of cultures } \rightarrow \\
\text { shaking (150 rpm) }\end{array}$ & Axillary bud & $\begin{array}{l}\text { Oryzalin; } 20-40 \\
\mu \mathrm{M} ; 24 \mathrm{~h}\end{array}$ & $\begin{array}{l}\text { Diploid } \rightarrow \text { tetraploid } \\
(2 n=4 x=40)\end{array}$ & Increase in cannabidiol (9\%) & {$[55]$} \\
\hline garlic & $\begin{array}{l}\text { Imbibed in colchicine soln. (5 } \\
\text { drops of } 4 \% \text { DMSO added) }\end{array}$ & Clove & $\begin{array}{l}\text { Colchicine; } \\
0.6 \% ; 24 \mathrm{~h}\end{array}$ & $\begin{array}{l}\text { Diploid } \rightarrow \text { tetraploid } \\
(2 n=4 x=32)\end{array}$ & $\begin{array}{l}\text { Increase in diallyl disulfide (15.13\%), } \\
\text { allyl methyl trisulfide (24.61\%) and } \\
\text { diallyl trisulfide (15.57\%) }\end{array}$ & {$[56]$} \\
\hline \multirow[t]{3}{*}{$\begin{array}{l}\text { Physalis } \\
\text { peruviana L. }\end{array}$} & Soaking in colchicine soln. & Seed & $\begin{array}{l}\text { Colchicine; } \\
0.6 \% ; 36 \mathrm{~h}\end{array}$ & $\begin{array}{l}\text { Diploid } \rightarrow \text { tetraploid } \\
(2 n=4 x=48)\end{array}$ & Increase in total flavonoid (88.7\%) & {$[57]$} \\
\hline & $\begin{array}{l}\text { Germinated seed with } 2-3 \\
\text { mm long root in colchicine } \\
\text { soln. }\end{array}$ & & $\begin{array}{l}\text { Colchicine; } \\
0.6 \% ; 24 h\end{array}$ & & Increase in total anthocyanin (9.1\%) & \\
\hline & Soaking in colchicine soln. & & $\begin{array}{l}\text { Colchicine; } \\
0.6 \% ; 24 \mathrm{~h}\end{array}$ & & Increase in total phenolic (NM) & \\
\hline $\begin{array}{l}\text { Citrus limon (L.) } \\
\text { Osbeck }\end{array}$ & $\begin{array}{l}\text { MS + colchicine; } 25 \pm 2{ }^{\circ} \mathrm{C} ; 16 \\
\text { h PP; } 50-60 \mu \mathrm{mol} / \mathrm{m}^{2} / \mathrm{s} \mathrm{LI}\end{array}$ & $\begin{array}{l}\text { Seed with } \\
\text { radicle }\end{array}$ & $\begin{array}{l}\text { Colchicine; } \\
0.025 \% ; 24 \text { h }\end{array}$ & $\begin{array}{l}\text { Diploid } \rightarrow \text { tetraploid } \\
(2 n=4 x=36)\end{array}$ & $\begin{array}{l}\text { Increase in essential oil and limonene } \\
(7 \%)\end{array}$ & {$[58]$} \\
\hline $\begin{array}{l}\text { Eucalyptus } \\
\text { polybractea RT } \\
\text { Baker }\end{array}$ & $\begin{array}{l}\text { Solid medium } \mathrm{M} 1+ \\
\text { colchicine; Dark; } 25^{\circ} \mathrm{C} \text {; shaking } \\
\text { at } 40 \mathrm{rpm}\end{array}$ & Shoot tip & $\begin{array}{l}\text { Colchicine; } \\
0.5 \% ; 4 \mathrm{~d}\end{array}$ & $\begin{array}{l}\text { Diploid } \rightarrow \text { tetraploid } \\
(2 n=4 x=44)\end{array}$ & Increase in essential oil (3\%) & {$[59]$} \\
\hline \multirow[t]{2}{*}{$\begin{array}{l}\text { Plantago } \\
\text { psyllium }\end{array}$} & $\begin{array}{l}\text { Colchicine treatment } \\
\text { (dissolved in } 2 \% \text { DMSO) }\end{array}$ & $\begin{array}{l}\text { Terminal } \\
\text { bud }\end{array}$ & $\begin{array}{l}\text { Colchicine; } \\
0.5 \% ; 24 \mathrm{~h}\end{array}$ & $\begin{array}{l}\text { Diploid } \rightarrow \text { tetraploid } \\
(2 n=4 x=24)\end{array}$ & Increase in carotenoid (1.5-fold) & {$[60]$} \\
\hline & NM & & $\begin{array}{l}\text { Trifluralin; } \\
22.5 \% ; 72 \mathrm{~h}\end{array}$ & & Increase in carotenoid (1.54-fold) & \\
\hline Plantago ovata & Soaking in colchicine soln. & Terminal & Colchicine; & Diploid $\rightarrow$ tetraploid & Increase in carotenoid content & {$[61]$} \\
\hline
\end{tabular}


Table 1 Antimitotic agent(s) and their influence on autopolyploidization and subsequent secondary metabolites production (arranged in chronological order) (Continued)

\begin{tabular}{|c|c|c|c|c|c|c|}
\hline Plant spp. & Treatment condition & $\begin{array}{l}\text { Treated } \\
\text { plant part }\end{array}$ & $\begin{array}{l}\text { Type, dosage } \\
\text { and exposure } \\
\text { duration of } \\
\text { antimitotic } \\
\text { agent(s) }\end{array}$ & $\begin{array}{l}\text { Resultant ploidy } \\
\text { level }\end{array}$ & $\begin{array}{l}\text { Effect on secondary metabolite } \\
\text { production }\end{array}$ & Reference \\
\hline & & bud & $\begin{array}{l}0.3 \% ; 24 \mathrm{~h} \\
\text { Trifluralin; } \\
22.5 \% ; 72 \mathrm{~h}\end{array}$ & $(2 n=4 x=16)$ & (approx. 1.83-fold) & \\
\hline $\begin{array}{l}\text { Thymus vulgaris } \\
\mathrm{L} \text {. }\end{array}$ & $\begin{array}{l}\text { Oryzalin (dissolved in } 1 \% \\
\text { DMSO) treatment } \rightarrow \text { sterile } \\
\mathrm{H}_{2} \mathrm{O} \text { washing } \rightarrow \text { culture in MS }\end{array}$ & $\begin{array}{l}\text { Nodal } \\
\text { segment }\end{array}$ & $\begin{array}{l}\text { Oryzalin; } 80 \mu \mathrm{M} \text {; } \\
24 \mathrm{~h}\end{array}$ & $\begin{array}{l}\text { Diploid } \rightarrow \text { tetraploid } \\
(2 n=4 x=60)\end{array}$ & $\begin{array}{l}\text { Essential oil content increase (from } \\
0.81 \text { to } 1.19 \%) \text {; increase in thymol } \\
(18.01 \%) \text { and carvacol }(0.49 \%)\end{array}$ & {$[62]$} \\
\hline \multirow[t]{3}{*}{$\begin{array}{l}\text { Melissa } \\
\text { officinalis L. }\end{array}$} & \multirow[t]{3}{*}{ Soaked in colchicine soln. } & \multirow[t]{3}{*}{ Seedling } & $\begin{array}{l}\text { Colchicine; } \\
0.1 \% ; 24 \mathrm{~h}\end{array}$ & \multirow[t]{3}{*}{$\begin{array}{l}\text { Diploid } \rightarrow \text { tetraploid } \\
(2 n=4 x=64)\end{array}$} & $\begin{array}{l}\text { Increase in carotenoid content (2.9- } \\
\text { fold) }\end{array}$ & \multirow[t]{3}{*}{ [63] } \\
\hline & & & $\begin{array}{l}\text { Colchicine; } \\
0.05 \% ; 24 \mathrm{~h}\end{array}$ & & Increase in phenolic content (4 times) & \\
\hline & & & $\begin{array}{l}\text { Colchicine; } \\
0.1 \% ; 48 \mathrm{~h}\end{array}$ & & $\begin{array}{l}\text { Increase in flavonoid content (4.93- } \\
\text { fold) }\end{array}$ & \\
\hline Lippia alba & $\begin{array}{l}\text { Inoculation in colchicine }+\mathrm{MS} \\
\text { medium }\end{array}$ & $\begin{array}{l}\text { Nodal } \\
\text { segment }\end{array}$ & $\begin{array}{l}\text { Colchicine; } \\
0.2 \% ; 72 \mathrm{~h} \\
\text { Colchicine; } \\
0.2 \% ; 4 \mathrm{~h}\end{array}$ & $\begin{array}{l}\text { Diploid } \rightarrow \text { tetraploid } \\
(2 \mathrm{n}=4 \mathrm{x}=60) \\
\text { Diploid } \rightarrow \text { mixoploid }\end{array}$ & $\begin{array}{l}\text { Increase in linalool content; } \\
\text { insignificant change in ctiral content }\end{array}$ & {$[64]$} \\
\hline $\begin{array}{l}\text { Zingiber } \\
\text { officinale } \\
\text { Roscoe cv. } \\
\text { 'Fengtou' } \\
\text { ginger }\end{array}$ & $\begin{array}{l}\text { MSL + colchicine soln. } \rightarrow \\
\text { shaking at } 150 \mathrm{rpm} \text { at } 23^{\circ} \mathrm{C} \\
\text { dark }\end{array}$ & $\begin{array}{l}\text { Stem } \\
\text { segment }\end{array}$ & $\begin{array}{l}\text { Colchicine; } \\
\text { 150mg/l; } 7 \mathrm{~d}\end{array}$ & $\begin{array}{l}\text { Diploid } \rightarrow \text { tetraploid } \\
(2 n=4 x=44)\end{array}$ & $\begin{array}{l}\text { Increase in carotenoids conc. (1.375- } \\
\text { fold) }\end{array}$ & {$[65]$} \\
\hline $\begin{array}{l}\text { Panax ginseng } \\
\text { Mayer }\end{array}$ & $\begin{array}{l}\text { MSL }+ \text { colchicine soln. } \rightarrow \\
\text { shaking at 100rpm } \rightarrow \text { dark }\end{array}$ & $\begin{array}{l}\text { Adventitious } \\
\text { root }\end{array}$ & $\begin{array}{l}\text { Colchicine; } \\
\text { 100mg/l; } 1 \mathrm{~d}\end{array}$ & $\begin{array}{l}\text { Tetraploid } \rightarrow \text { mutant } \\
\text { (tetraploid) }\end{array}$ & $\begin{array}{l}\text { Increase in ginsenoside production } \\
\text { ( } 4.85 \text {-fold) }\end{array}$ & {$[66]$} \\
\hline $\begin{array}{l}\text { Stevia } \\
\text { rebaudiana }\end{array}$ & Soaked in colchicine soln. & Seed & $\begin{array}{l}\text { Colchicine; } \\
0.2 \% ; 24 \mathrm{~h}\end{array}$ & $\begin{array}{l}\text { Diploid } \rightarrow \text { tetraploid } \\
(2 n=4 x=44)\end{array}$ & $\begin{array}{l}\text { Increase in rebaudioside-A content } \\
(2.84 \%)\end{array}$ & {$[67]$} \\
\hline Artemisia cina & Soaked in colchicine soln. & Shoot & $\begin{array}{l}\text { Colchicine; } 100 \\
\mathrm{mg} / \mathrm{l}\end{array}$ & $\begin{array}{l}\text { Diploid } \rightarrow \text { tetraploid } \\
(2 n=4 x=36)\end{array}$ & $\begin{array}{l}\text { Increase in quercetin content (1.34- } \\
\text { fold); kaempferol content (1.47-fold) }\end{array}$ & {$[68]$} \\
\hline Artemisia cina & NM & NM & $\begin{array}{l}\text { Colchicine; NM; } \\
\text { NM }\end{array}$ & $\begin{array}{l}\text { Diploid } \rightarrow \text { tetraploid } \\
(2 n=4 x=36)\end{array}$ & Increase in artemisinin content (NM) & {$[69]$} \\
\hline \multirow[t]{2}{*}{$\begin{array}{l}\text { Solanum } \\
\text { tuberosum }\end{array}$} & In vitro colchicine treatment & $\begin{array}{l}\text { (Solanum } \\
\text { tuberosum } \times \\
\text { Solanum } \\
\text { kurtzianum) }\end{array}$ & $\begin{array}{l}\text { Colchicine; NM; } \\
\text { NM }\end{array}$ & $\begin{array}{l}\text { Diploid } \rightarrow \text { tetraploid } \\
(2 \mathrm{n}=4 \mathrm{x}=48) \\
\text { (Allotetraploid) }\end{array}$ & Increase in sesquiterpenes (22-fold) & {$[70]$} \\
\hline & Oryzalin treatment & $\begin{array}{l}\text { Diploid line } \\
\text { (Solanum } \\
\text { kurtzianum) }\end{array}$ & $\begin{array}{l}\text { Oryzalin; NM; } \\
\text { NM }\end{array}$ & $\begin{array}{l}\text { Diploid } \rightarrow \text { tetraploid } \\
(2 n=4 x=48) \\
\text { (Autotetraploid) }\end{array}$ & Increase in sesquiterpenes (6-fold) & \\
\hline
\end{tabular}

2-IP 2-isopentenyl adenine; B5 Gamborg's B5 media [71]; BA N $\mathrm{N}^{6}$-benzyladenine; $d$ days, DMSO dimethyl sulfoxide; $L I$ light intensity; $M 1$ media [woody basal salt mixture $(2.3 \mathrm{~g} / \mathrm{l})+$ Murashige and Skoog modified vitamins $(1000 \mathrm{x})(1 \mathrm{ml} / \mathrm{l})+$ Sucrose $(25 \mathrm{~g} / \mathrm{l})+2 \mathrm{IP}(3 \mu \mathrm{M})+\mathrm{Agar}(7 \mathrm{~g} / \mathrm{l})]$; $\mathrm{m}$ months; min minutes; MS Murashige and Skoog [72]; MSL MS Liquid Media; NAA a-naphthalene acetic acid; NM not mentioned; PP photoperiod; rpm rotation per minute; r.t. room temperature; SAM shoot apical meristem; TDZ thidiazuron; $w$ weeks

young meristematic portions are more flexible to polyploidy induction, since they provide better permeability to the antimitotic chemicals; furthermore, as they contain fresh DNA as a result, duplication of genetic content becomes easier and more effective. Across the recently published research reports, it has been found that shoot tips, root tip, shoot apical meristem, petiole, nodal segments, callus, stem disc and leaf were successfully utilized as explants (Table 1). Seeds have also been used for the initiation of polyploidization experiments (Table 1). Other meristematic regions that were investigated into are terminal buds [60], adventitious buds [51], nodal buds [19], cluster buds [31] and axillary buds [55]. As a novel approach, diploid shooty teratomas obtained from Agrobacterium tumefasciens-mediated transformation were utilized for production of stable high vincristine, yielding tetraploid clones in Catharanthus roseus [11]. Clove explants in garlic were employed by Yousef and Elsadek [56]. Another unconventional explant that was utilized are protocorm-like bodies by [41] for tetraploid induction in Dendrobium hybrids. Tsuro et al. [32] have used callus for in vitro autoployploidy induction in Chamaemelum nobile L. Explant tissues should always receive uniform treatment otherwise it may lead to production of mixoploids having variable cytology [79]. Such results were found in the findings of Mansouri and Bagheri [36], although an 

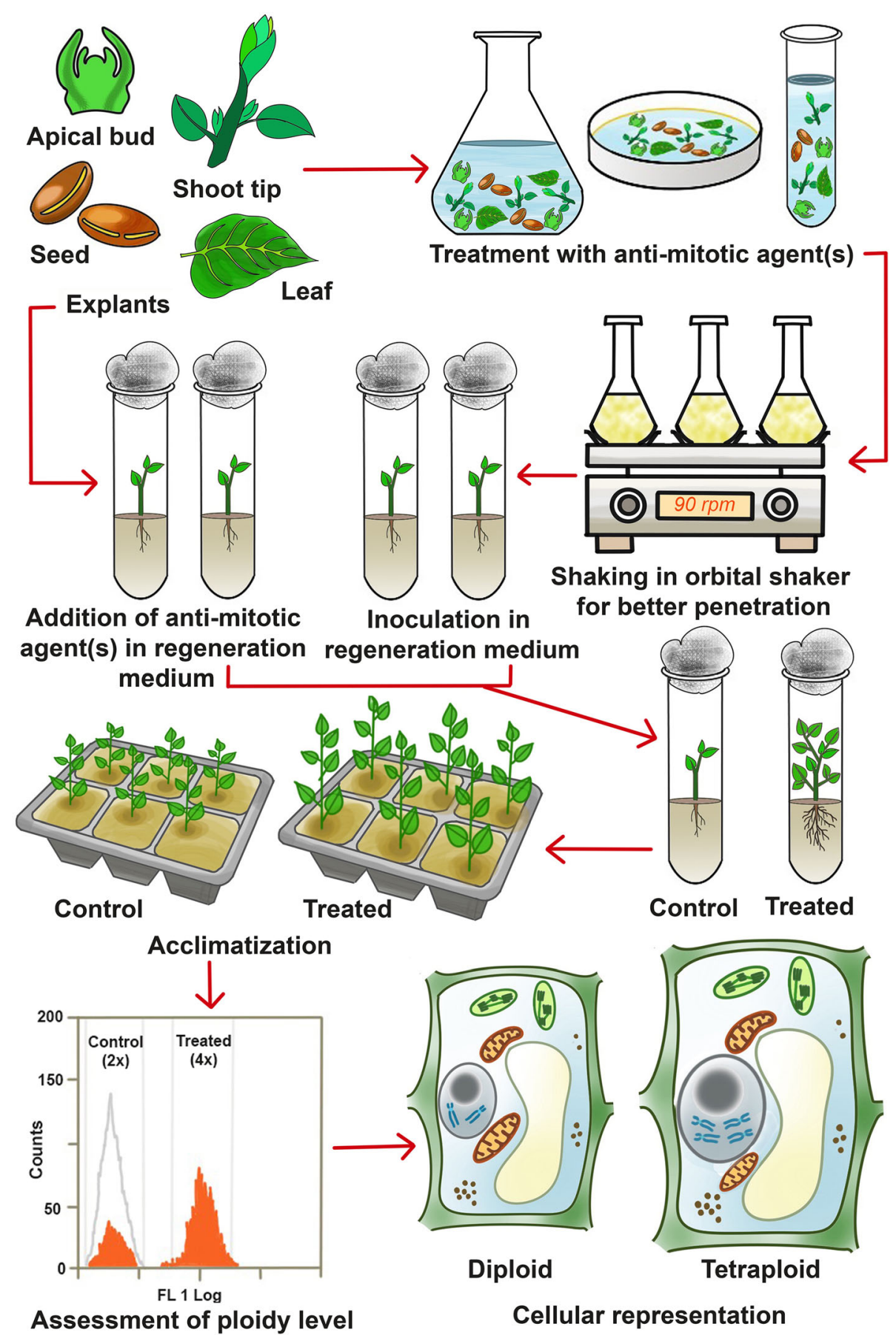

Fig. 1 Diagrammatic representation of in vitro induction of autopolyploidization (diagram is not in scale) (Source: unpublished diagram of Saikat Gantait)

increase in cannabinoid content was found in mixoploids over tetraploids. From the different results obtained, shoot tip explants were the most effective during enhancement of phyto-biochemicals in induced autoploids (2-4-fold on average), whereas seeds and apical buds yielded similar improvements (1.5-2.5 times). Such effectivity could be attributed to their higher meristematic activity. Other explant sources (callus, leaf, somatic embryos, etc.) showing redifferentiative regeneration presented 2-4-fold increment in phytochemicals but there remains a chance of occurrence of somaclonal variants and hence reproducibility is compromised. It must be borne in mind that ameliorated secondary metabolite extraction through induced polyploidy asks for uniform and homogenized 
phytochemical production and end-product realization. Divergent explants being in their divergent stages of physiological development ramify divergent responses. Differential responses of the explants engaged could be attributed to different factors such as physiological, morphological, biochemical or genetic factors [6]. Meristematic status as well as size of explants favours effective manipulation into desired experimental outcome [80]. Furthermore, different explants have different regenerative capabilities. Hence, apical meristems (shoot or root) with active cell divisional status are more amenable to ploidy alterations and in regeneration of autopolyploid shootlets. On the other hand, other explant sources (such as calli and somatic embryos) with varied tissue organizations might show experimental discrepancies into the realization of expected result.

\section{Influence of type, dosage and exposure duration of antimitotic agent(s)}

Antimitotic agents are those group of chemicals that impede spindle formation during mitotic cell division, thereby resulting in the restitution of nucleus to contain all the chromosomes. As a result, the chromosome number of the cell doubles. Conversion to higher ploidy levels comprised of diploids is altered to triploids, tetraploids and octaploids. In the majority of the studies, the usage of colchicine as an antimitotic chemical was reported. However, other mitotic-toxic substances such as oryzalin, trifluralin were also put into use. Colchicine is a slow penetrating chemical impacting epidermal layer, subepidermal layer or entire tissue depending upon its duration of exposure. It mostly affects the dividing cells through interception of spindle fibre formations. Frequent treatments are applied at brief intermissions to juvenile tissues since only a limited number of cells remain at their dividing stage at a particular point of time. 'Cotton plug' method [81] involving intermittent colchicine application presents an instance to the above situation. This method is advantageous in the sense that the chemical saturated cotton preserves moisture and ensures better contact with the chemical thereby effecting better cellular interaction and prospective ploidy level changes. However, it must be ensured that the polyploidy inducing chemical is supplied regularly otherwise the explant might dry. Varied doses of colchicine were applied $(0.01 \%, 0.05 \%, 0.1 \%, 0.2 \%, 0.25 \%, 0.3 \%, 0.5 \%$, $0.6 \%, 1 \%, 1.5 \%$, and $2.5 \%$; w/v) for successful polyploidization (Table 1). Very lower $(<1 \%)$ concentrations of colchicine were less productive resulting in less frequent polyploidization, whereas higher $(>2 \%)$ concentrations exhibited detrimental effects on the exposed plant tissues. The most efficient dose of colchicine was recorded to be $0.1 \%$ in terms of higher frequency polyploid development and higher production of secondary metabolites from those polyploids as well. In comparison to colchicine, there are fewer reports utilizations of trifluralin, oryzalin or amiprophos-methyl as antimitotic agents for autopolyploid induction (Table 1). Even though these reports testified significant improvement in secondary metabolite productions in (trifluralin-, oryzalin- or amiprophos-methyl-induced) tetraploids (1.5-2-fold), but the enhancement were comparatively lower to that of the colchiploids (colchicine-induced polyploids) (1.54-fold on an average). Preferences for the colchicine as an antimitotic agent account for its better action than other polyploidy inducing chemicals (such as trifluralin, oryzalin and amiprophos-methyl) due its better penetrance and quicker mobilization through the tissues. A careful study of the published reports established the fact that in case of successful colchicine treatment, usually lower concentrations were accompanied with longer exposure duration and vice versa. The treatment durations ranged from min to days. Shortest treatment being 20-40 min in Andrographis paniculata [47]. However, such a short exposure intensity was supported via 'pretreatment soaking' in sterile water and subsequent 'low temperature shock' (Table 1). Such predisposition presumably improved seed germination and in process exposed the protruded shoot apical meristems to colchicine. In terms of exposure time, the longest duration was recorded as 37 days in Echinacea purpurea L. [28], wherein colchicine was added to the basal media resulting in high frequency tetraploids and octaploids along with augmented cichoric acid production. Addition of antimitotic agents to the basal media increased the exposure time which resulted in higher ploidy level in individual plants. However, low doses of colchicine were added to the media so as to prevent long time exposurerelated injury to the tissues. Le et al. [66] have reported initial inoculation in colchicine supplemented basal media for the respective treatment durations and subsequent culturing in fresh colchicine free basal media. The most promising treatment duration was $24 \mathrm{~h}$ (Table 1 ), wherein maximum yield of secondary metabolites was recovered. For the other antimitotic agents (such as trifluralin, oryzalin and amiprophos-methyl), treatment duration could not be determined due to lack of comprehensive investigation. Rahman [35] reported $120 \mathrm{~h}$ of trifluralin exposure in Aquilaria malaccensis Lamarck. resulting in production of tetraploids, revealing the presence of sesquiterpenes. Similarly, oryzalin treatment was done mostly for $24 \mathrm{~h}$ except for Pliankong et al. [34] wherein exposure for only $6 \mathrm{~h}$ in Capsicum frutescens $\mathrm{L}$. resulted in tetraploids with elevated capsaicin levels. Different durations of treatments have shown to give different responses [80]. As discussed earlier, exposures of longer duration with lower doses of antimitotic agent have been more effective than exposures of shorter 
duration coupled with higher concentrations. Both the extremities of doses stand unprofitable either due to non-effectivity or lethality [61, 79]. Different experimental results testify to the corollary that varied autopolyploids like mixoploids and tetraploids have been obtained due differential durations of treatment [64]. Changes in secondary cellular metabolism inflicted due to varied colchicine durations were also reported in recent past $[57,63]$. Such subtlety in results across the different published research investigations could be due to differences in chemical absorption in the different tissues of the explants over time and consequent chromosome multiplicative interactions. Differences in durations could also be accounted to explant variedness (size, meristematic tissue status, presence of external cell surface substances like cuticle, waxes, seed coat) and species dependent amenability to artificially induced ploidy changes [80].

\section{Influence on secondary metabolite production}

In medicinal plants, secondary metabolites produced per unit biomass are of immense economic importance. Necessarily, in this scenario, doubling of the genomic content of cells propounds functionalized genome multiplications, enhanced protein synthesis and thereby amplified secondary metabolite biosynthesis among the induced autotetraploids (Fig. 2). Alterations in cellular dynamics is positively influenced owing to pronounced increase in cell size, organelle size and numbers, transcriptome products, net photosynthetic rate and upraised metabolistic pathways. Accumulation of favourable 'like' alleles in one organism coupled with induced doubling of chromosome number further aids in the pharma-chemical productivity and promotes partitioning of cell energy resources for secondary metabolism and trimming down of lengthy pathways via improvised enzyme kinetics [4]. This holds an evolutionary significance as energy saving plants are more favoured. Positive mutagenic changes like deletions, additions translocations or insertions restructure genomic architecture and invoke epigenetic permutations (DNA methylations, gene-silencing). Induced genome multiplications could also impinge cellular homeostatics due to imposed shock leading to inconsistent biochemical production [5, 82]. Table 1 represents a survey of available literature that reveal that there is an accrual in secondary metabolites production among the induced autopolyploids. Such amelioration brought about was recorded to be 2-4 times. Secondary metabolites targeted were alkaloids [52], phenolic acids like, cichoric acid [15], caffeic acid [22], terpenoids [10], glycosides [51], essential oils [27] and flavonoids [37]. However, findings of Caruso et al. [13] revealed that similar or lower quantities of phenylpropanoids and metabolites were produced in induced tetraploids of Solanum bulbocastanum in comparison to their diploid counterparts.
These results differ from the same researcher's previous findings in Solanum commersonii [12] wherein the increment in phenylpropanoid content ( 2 times $)$ was observed. Thus, such investigations establish the fact that species-related differences eventually affect polyploidy induction with respect to phytometabolite synthesis. Claims of lower production of phenolic compounds were found in the experimental reports of Ghimire et al. [29], wherein hexaploids of Miscanthus $\times$ giganteus yielded less than their corresponding triploids. However, it was observed that there was quantitative alteration in the component phenolic acids that were produced in the hexaploids as compared to the triploids. Supposedly, there was modification in the gene expression in hexaploids leading to repression and/or de-repression of genes for phenolic acid biosynthesis. Such quantitative and non-quantitative changes leading to biosynthesis of novel phytochemicals originally not detected in their diploid parents were also reported most recently [64, 65, 70]. Cara et al. [70] in their experimental findings documented comparative variations in the secondary biometabolite productions among induced autopolyploids and allopolyploids of Solanum tuberosum and Solanum kurtzianum (Table 1). Obtained altered secondary metabolism as exhibited in their results find relevance in stress resistance breeding due to identification and development of lines producing more amount of stress tolerance conferring osmolytes. Similar opinions of modulations in metabolism favouring plant species adaptability were opined by Kumar [82]. Li et al. [28] in their findings in Echinacea purpurea reported cichoric acid enhancement through tetraploid and subsequent octaploid induction. From the results, it can be deduced that the rate of increment in metabolite production increases in tetraploids and is further improved in octaploids. Hence, manifold multiplication of allelic constituents further improvises metabolism pathways through complementation in enzyme productions and action. Such polyploidy induction could be yet another remunerative approach for in vitro autopolyploidization-mediated crop improvement. However, the above-mentioned fact contradicts with opinions of Lavania et al. [4], wherein it was hypothesized that cytosine methylation in genomic regions in tandem with ploidy upliftment diminishes biometabolites production. Occasionally appearing mixoploids (organisms with differential chromosome numbers across cells; chimera) express enrichment of pharmaceutical metabolites as seen in Stevia rebaudiana (Bertoni) (13.5\% increase in steviosides content) [24]. Similarly, Mansouri and Bagheri [36] in their study reported an increase in cannabinoids in induced mixoploids over tetraploids. Such results were due to decreased trichomes in tetraploids than mixoploids, hinting at probable negatively correlated gene interactions. In this context, Herawati et al. [69] reported increased numbers of glandular trichomes correlating positively with artemisinin 


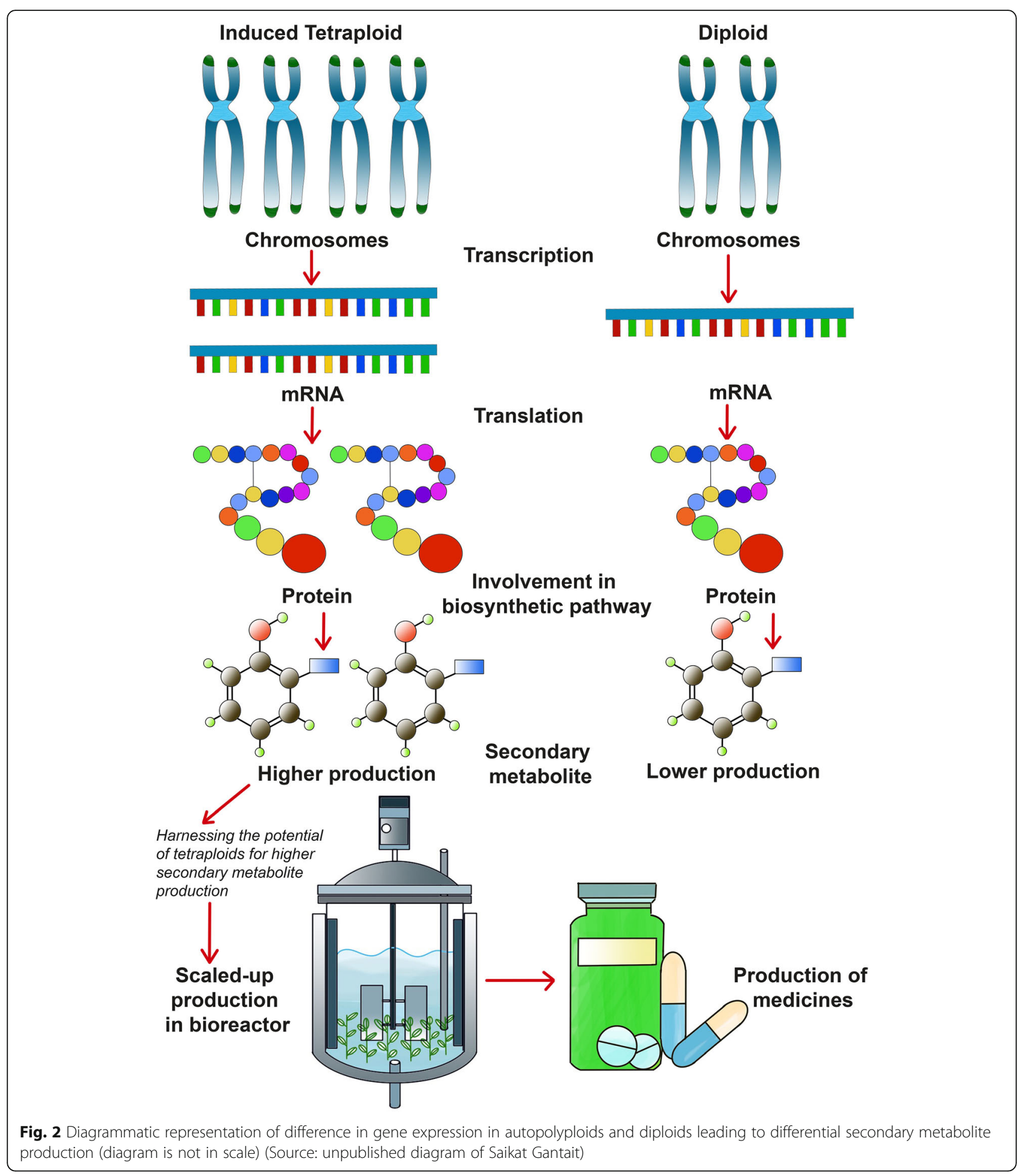

production. Throughout the different studies, it can also be concluded that enhancement in bio-metabolites productions upon induced chromosome doubling is not exactly twice but the ameliorations are more than their diploid counterparts (Table 1). Improvements in secondary biometabolites productions could be due to morphological, physiological as well as genetic manifestations engendered upon by induced autoploids. Some of such illustrative causes of autoploidy-mediated secondary metabolite augmentation are increase in stomatal sizes and densities leading to increased photosynthates output [67], heterosis and gene redundancy imparting transgressive meliorism [56, 
66, 68]. Shmeit et al. [62] reckoned that improvised primary metabolism could be the presumptive cause of ameliorated secondary metabolism. Modified enzyme profiles and gene expressions also play role in this refinement.

\section{Conclusions}

Autopolyploidy is supposed to have an effect on the plant vigour in terms of biomass production and phytochemical biosynthesis. Proliferation in morphological traits and change in cytological structures coupled with novel proteomic features and accumulated secondary phyto-pharmaceuticals are major advantages established in induced autopolyploid cultures. Choice of suitable metaphase inhibitors or the polyploidy inducers is important as these are major players in the process. Of the different antimitotic agents, colchicine has proved to be better in producing stable and functional autoploids in higher frequencies. Potency of colchicine is due to its better cell to cell mobilization and tissue permeation, thereby resulting in more microtubule blockage during divisional stages and producing autopolyploids. Of the different explants, meristematic shoot tips exhibited higher ploidy conversions. Optimized results were obtained at $0.1 \%$ for $24 \mathrm{~h}$ of colchicine resulting in desired ploidy level manipulations and improved secondary metabolism. Improvements in biometabolite synthesis stems from improvised enzymatic functioning. Formulation of optimized protocol in different medicinal crops of value enables coordinated in vitro omics studies, contributes to crop evolution studies and unravels unsolved taxonomic queries. This tool in conjunction with nextgeneration sequencing techniques, hairy root culture technologies and other biotechnological interventions will certainly help researchers in future plant breeding strategies. The demand for medicinally valued plants for treatment and cure of different diseases has increased worldwide. Hence, keeping in mind about the commercial and scientific realizations, ameliorated secondary bio-metabolite production via in vitro induced autopolyploidy emerges as a constructive strategy for morphophysio-genetic crop improvement.

\section{Abbreviations}

BA N $N^{6}$ : Benzyladenine; DMSO: Dimethyl sulfoxide; MS: Murashige and Skoog; MSL: MS liquid media; NAA: a-Naphthalene acetic acid; TDZ: Thidiazuron

\footnotetext{
Acknowledgements

Authors acknowledge the e-library assistance from the Bidhan Chandra Krishi Viswavidyalaya, West Bengal, India. We are further thankful to the anonymous reviewer(s) and the editor of this article for their critical comments and suggestions on the manuscript.
}

\section{Authors' contributions}

SG conceived the idea of the review and surveyed the literature; SG and EM drafted the manuscript equally; SG scrutinized and corrected the manuscript to its final version. Both the authors read and approved the final version of the manuscript prior to its submission.
Funding

Self-funded.

Availability of data and materials

The datasets used and/or analyzed during the current study are available from the corresponding author on reasonable request.

Ethics approval and consent to participate

Not applicable.

Consent for publication

Not applicable.

\section{Competing interests}

The authors declare that they have no competing interests.

Received: 23 October 2020 Accepted: 22 December 2020

Published online: 08 January 2021

\section{References}

1. Ranney TG (2006) Polyploidy: from evolution to new plant development. Combined Proc Int Plant Propagators' Soc 56:137-142

2. Gantait S, Mandal N, Bhattacharyya S, Das PK (2011) Induction and identification of tetraploids using in vitro colchicine treatment of Gerbera jamesonii bolus cv. Sciella. Plant Cell Tiss Org Cult 106:485-493

3. Moghbel N, Borujeni MK, Bernard F (2015) Colchicine effect on the DNA content and stomata size of Glycyrrhiza glabra var. glandulifera and Carthamus tinctorius L. cultured in vitro. J. Genet Eng Biotechnol 13:1-6

4. Lavania UC, Srivastava S, Lavania S, Basu S, Misra NM, Mukai Y (2012) Autopolyploidy differentially influences body size in plants, but facilitates enhanced accumulation of secondary metabolites, causing increased cytosine methylation. Plant J 71:539-549

5. Iannicelli J, Guariniello J, Tossi VE, Regalado JJ, Di Ciaccio L, van Baren CM, Álvarez SP, Escandón AS (2020) The "polyploid effect" in the breeding of aromatic and medicinal species. Sci Hortic 260:108854

6. Salma U, Kundu S, Mandal N (2017) Artificial polyploidy in medicinal plants: advancement in the last two decades and impending prospects. J Crop Sci Biotechnol 20:9-19

7. Niazian M, Nalousi AM (2020) Artificial polyploidy induction for improvement of ornamental and medicinal plants. Plant Cell Tiss Org Cult 142:447-469

8. Dhawan OP, Lavania UC (1996) Enhancing the productivity of secondary metabolites via induced polyploidy: a review. Euphytica 87:81-89

9. Xing SH, Guo XB, Wang Q, Pan QF, Tian YS, Liu P, Zhao JY, Wang GF, Sun $X F$, Tang KX (2011) Induction and flow cytometry identification of tetraploids from seed-derived explants through colchicine treatments in Catharanthus roseus (L.) G. Don. Biomed Res Int 2011:793198

10. Kaensaksiri T, Soontornchainaksaeng P, Soonthornchareonnon N, Prathanturarug S (2011) In vitro induction of polyploidy in Centella asiatica (L.) urban. Plant Cell Tiss Org Cult 107:187

11. Begum F (2011) Augmented production of vincristine in induced tetraploids of Agrobacterium transformed shooty teratomas of Catharanthus roseus. Med Plant 3:59-64

12. Caruso I, Lepore L, De Tommasi N, Dal Piaz F, Frusciante L, Aversano R, Garramone R, Carputo D (2011) Secondary metabolite profile in induced tetraploids of wild Solanum commersonii dun. Chem Biodivers 8:2226-2237

13. Caruso I, Dal Piaz F, Malafronte N, De Tommasi N, Aversano R, Zottele CW, Scarano MT, Carputo D (2013) Impact of ploidy change on secondary metabolites and photochemical efficiency in Solanum bulbocastanum. Nat Prod Commun 8:1934578X1300801011

14. Ahmadi T, Jafarkhani Kermani M, Mashayekhi K, Hasanloo T, Shariatpanahi ME (2013) Comparing plant morphology, fertility and secondary metabolites in Rosa hybrida cv. Iceberg and its chromosome-doubled progenies. Int Res J Appl Basic Sci 4:3840-3849

15. Abdoli M, Moieni A, Badi HN (2013) Morphological, physiological, cytological and phytochemical studies in diploid and colchicine-induced tetraploid plants of Echinacea purpurea (L.). Acta Physiol Plant 35:2075-2083

16. Yadav AK, Singh S, Yadav SC, Dhyani D, Bhardwaj G, Sharma A, Singh B (2013) Induction and morpho-chemical characterization of Stevia rebaudiana colchiploids. Indian J Agric Sci 83:159-165 
17. Ghotbi Ravandi E, Rezanejad F, Zolala J, Dehghan E (2013) The effects of chromosome-doubling on selected morphological and phytochemical characteristics of Cichorium intybus L. J Hortic Sci Biotech 88:701-709

18. Dixit V, Chaudhary BR (2014) Colchicine-induced tetraploidy in garlic (Allium sativum L.) and its effect on allicin concentration. J Hortic Sci Biotech 89: 585-591

19. Gomes SSL, Saldanha CW, Neves CS, Trevizani M, Raposo NRB, Notini MM, de Oliveira Santos M, Campos JMS, Otoni WC, Viccini LF (2014) Karyotype, genome size, and in vitro chromosome doubling of Pfaffia glomerata (Spreng.) Pedersen. Plant Cell Tiss Org Cult 118:45-56

20. Zahedi AA, Hosseini B, Fattahi M, Dehghan E, Parastar H, Madani H (2014) Overproduction of valuable methoxylated flavones in induced tetraploid plants of Dracocephalum kotschyi Boiss. Bot Stud 55:22

21. Thong-on W, Arimatsu P, Pitiporn S, Soonthornchareonnon N, Prathanturarug S (2014) Field evaluation of in vitro-induced tetraploid and diploid Centella asiatica (L.) urban. J Nat Med 68:267-273

22. Xu CG, Tang TX, Chen R, Liang CH, Liu XY, Wu CL, Yang YS, Yang DP, Wu H (2014) A comparative study of bioactive secondary metabolite production in diploid and tetraploid Echinacea purpurea (L.) Moench. Plant Cell Tiss Org Cult 116:323-332

23. Dixit V, Verma S, Chaudhary BR (2015) Changes in ploidy and its effect on thymoquinone concentrations in Nigella sativa L. seeds. J Hortic Sci Biotech 90:537-542

24. Hegde SN, Rameshsing CN, Vasundhara M (2015) Characterization of Stevia rebaudiana Bertoni polyploids for growth and quality. Med Plant 7:188-195

25. Tavan M, Mirjalili MH, Karimzadeh G (2015) In vitro polyploidy induction: changes in morphological, anatomical and phytochemical characteristics of Thymus persicus (Lamiaceae). Plant Cell Tiss Org Cult 122:573-583

26. Rameshsing CN, Hegde SN, Vasundhara M (2015) Enhancement of steviol glycosides in stevia (Stevia rebaudiana Bertoni) through induction of polyploidy. Curr Trend Biotechnol Pharma 9:141-146

27. Hannweg K, Visser G, de Jager K, Bertling I (2016) In vitro-induced polyploidy and its effect on horticultural characteristics, essential oil composition and bioactivity of Tetradenia riparia. South Afr J Bot 106:186-191

28. Li Q, Yang Y, Wu H (2016) In vitro segregation of tetraploid and octoploid plantlets from colchicine-induced ploidy chimeras in Echinacea purpurea L. HortSci 51:549-557

29. Ghimire BK, Seong ES, Nguyen TX, Yoo JH, Yu CY, Kim SH, Chung IM (2016) Assessment of morphological and phytochemical attributes in triploid and hexaploid plants of the bioenergy crop Miscanthus $\times$ giganteus. Ind Crop Prod 89:231-243

30. Iannicelli J, Elechosa MA, Juarez MA, Martinez A, Bugallo V, Bandoni AL, Escandon AS, Van Bare CM (2016) Effect of polyploidization in the production of essential oils in Lippia integrifolia. Ind Crop Prod 81:20-29

31. Yan HJ, Xiong Y, Zhang HY, He ML (2016) In vitro induction and morphological characteristics of octoploid plants in Pogostemon cablin. Breed Sci 66:169-174

32. Tsuro M, Kondo N, Noda M, Ota K, Nakao Y, Asada S (2016) In vitro induction of autotetraploid of Roman chamomile (Chamaemelum nobile L.) by colchicine treatment and essential oil productivity of its capitulum. In Vitro Cell Dev Biol-Plant 52:479-483

33. AV K, NS C, MA C, RH A, MB K (2017) In vitro enhancement of bacoside in brahmi (Bacopa monnieri) using colchicine. J Plant Biochem Physiol 5:1-6

34. Pliankong P, Suksa-Ard P, Wannakrairoj S (2017) Effects of colchicine and oryzalin on polyploidy induction and production of capsaicin in Capsicum frutescens L. Thai J Agric Sci 50:108-120

35. Rahman SSBA (2017) Enhancement of key chemical constituents in Aquilaria malaccensis Lamarck (Karas) through in vitro polyploidization PhD Thesis, Universiti Putra Malaysia

36. Mansouri H, Bagheri M (2017) Induction of polyploidy and its effect on Cannabis sativa L. In: Cannabis sativa L.-Dotany and biotechnology. Springer, Cham, pp 365-383

37. Chung HH, Shi SK, Huang B, Chen JT (2017) Enhanced agronomic traits and medicinal constituents of autotetraploids in Anoectochilus formosanus Hayata, a top-grade medicinal orchid. Molecules 22:1907

38. Noori SAS, Norouzi M, Karimzadeh G, Shirkool K, Niazian M (2017) Effect of colchicine-induced polyploidy on morphological characteristics and essential oil composition of ajowan (Trachyspermum ammi L.). Plant Cell Tiss Org Cult 130:543-551

39. Javadian N, Karimzadeh G, Sharifi M, Moieni A, Behmanesh M (2017) In vitro polyploidy induction: changes in morphology, podophyllotoxin biosynthesis, and expression of the related genes in Linum album (Linaceae). Planta 245:1165-1178

40. Shin JH, Ahn YG, Jung JH, Woo SH, Kim HH, Gorinstein S, Boo HO (2017) Identification and characterization of diploid and Tetraploid in Platycodon grandiflorum. Plant Foods Hum Nutr 72:13-19

41. Grosso V, Farina A, Giorgi D, Nardi L, Diretto G, Lucretti S (2018) A high-throughput flow cytometry system for early screening of in vitro made polyploids in Dendrobium hybrids. Plant Cell Tiss Org Cult 132: $57-70$

42. Kundu S, Salma U, Ali MN, Mandal N (2018) In vitro tetraploidization for the augmentation of wedelolactone in Sphagneticola calendulacea (L.) Pruski. Acta Physiol Plant 40:215

43. Zhang H, An S, Hu J, Lin Z, Liu X, Bao H, Chen R (2018) Induction, identification and characterization of polyploidy in Stevia rebaudiana Bertoni. Plant Biotechnol 35:81-86

44. Salma U, Kundu S, Hazra AK, Ali MN, Mandal N (2018) Augmentation of wedelolactone through in vitro tetraploid induction in Eclipta alba (L.) Hassk. Plant Cell Tiss Org Cult 133:289-298

45. Mahdi SA, Meena CM, Tholakabavi A (2018) Induction of genetic variability by colchicine treatment in Stevia rebaudiana Bertoni. Al-Qadisiyah J Pure Sci 23:161-173

46. Wei KH, Xu JP, Li LX, Cai JY, Miao JH, Li MH (2018) In vitro induction and generation of tetraploid plants of Sophora tonkinensis Gapnep. Pharmacog Mag 14:149

47. Qi-Qing LI, ZHANG J, Ji-Hua LIU, Bo-Yang YU (2018) Morphological and chemical studies of artificial Andrographis paniculata polyploids. Chin J Nat Med 16:81-89

48. Chen EG, Tsai KL, Chung HH, Chen JT (2018) Chromosome doublingenhanced biomass and dihydrotanshinone I production in Salvia miltiorrhiza, a traditional Chinese medicinal plant. Molecules 23:3106

49. Li M, Ding B, Huang W, Pan J, Ding Z, Jiang F (2018) Induction and characterization of tetraploids from seeds of Bletilla striata (Thunb.) Reichb. F. Biomed Res Int 2018:3246398

50. Basu S, Lodh D (2018) Artificial induction of polyploidy in Andrographis paniculata (Burm. F.) wall. Ex Nees. J Indian Bot Soc 97:21-28

51. Xiang ZX, Tang XL, Liu WH, Song CN (2019) A comparative morphological and transcriptomic study on autotetraploid Stevia rebaudiana (Bertoni) and its diploid. Plant Physiol Biochem 143:154-164

52. Al-Taweel SK, Al-Amrani HA, Al-Rawi TK (2019) Induction and flow cytometry, GC-MS identification of tetraploids through colchicine treatments in Datura stramonium L. Plant Arch 19:241-250

53. Li Y, Yang J, Song L, Qi Q, Du K, Han Q, Kang X (2019) Study of variation in the growth, photosynthesis, and content of secondary metabolites in Eucommia triploids. Trees 33:817-826

54. Inthima P, Sujipuli K (2019) Improvement of growth and bacoside production in Bacopa monnieri through induced autotetraploidy with colchicine. Peer I 7:e7966

55. Parsons JL, Martin SL, James T, Golenia G, Boudko EA, Hepworth SR (2019) Polyploidization for the genetic improvement of Cannabis sativa. Front Plant Sci 10:476

56. Yousef EAA, Elsadek MA (2020) A comparative study of morphological and volatile oil composition characteristics in diploid and tetraploid garlic plants. Egypt J Hortic 46:295-308

57. Çömlekçioğlu N, Özden M (2019) Effects of colchicine application and ploidy level on fruit secondary metabolite profiles of goldenberry (Physalis peruviana L.). Appl Ecol Environ Res 18:289-302

58. Bhuvaneswari G, Thirugnanasampandan R, Gogulramnath M (2019) Effect of colchicine induced tetraploidy on morphology, cytology, essential oil composition, gene expression and antioxidant activity of Citrus limon (L.) Osbeck. Physiol Mol Biol Plants 26:271-279

59. Fernando SC, Goodger JQ, Chew BL, Cohen TJ, Woodrow IE (2019) Induction and characterisation of tetraploidy in Eucalyptus polybractea RT baker. Ind Crop Prod 140:111633

60. Sabzehzari M, Hoveidamanesh S, Modarresi M, Mohammadi V (2019a) Morphological, anatomical, physiological, and cytological studies in diploid and tetraploid plants of Plantago psyllium. Plant Cell Tiss Org Cult 139: 131-137

61. Sabzehzari M, Hoveidamanesh S, Modarresi M, Mohammadi V (2019b) Morphological, anatomical, physiological, and cytological studies in diploid and tetraploid plants of Ispaghul (Plantago ovata Forsk.). Genet Resour Crop Evol 67:129-137 
62. Shmeit YH, Fernandez E, Novy P, Kloucek P, Orosz M, Kokoska L (2020) Autopolyploidy effect on morphological variation and essential oil content in Thymus vulgaris L. Sci Hortic 263:109095

63. Talei D, Fotokian MH (2020) Improving growth indices and productivity of phytochemical compounds in lemon balm (Melissa officinalis L.) through induced polyploidy. BioTechnol 101:215-226

64. Julião SA, Ribiero CDV Lopes JML, Matos EMD, Reis AC, Peixoto PHP, Machado MA, Azevedo ALS, Grazul RM, Campos JMSD, Viccini LF (2020) Induction of synthetic polyploids and assessment of genoic stability in Lippia alba. Front Plant Sci 11:292

65. Zhou J, Guo F, Fu J, Xiao Y, Wu J (2020) In vitro polyploid induction using colchicine for Zingiber officinale roscoe cv. 'Fengtou' ginger. Plant Cell Tiss Org Cult 142:87-94

66. Le KC, Ho TT, Lee JD, Paek KY, Park SY (2020) Colchicine mutagenesis from long-term cultured adventitious roots increases biomass and ginsenoside production in wild ginseng (Panax ginseng Mayer). Agronomy 10:785

67. Talei D, Nekouei MN, Mardi M, Kadkhodaei S (2020) Improving productivity of steviol glycosides in Stevia rebaudiana via induced polyploidy. J Crop Sci Biotech 23:301-309

68. Kasmiyati S, Kristiani EBE, Herawati MM (2020) Effect of induced polyploidy on plant growth, chlorophyll and flavonoid content of Artemisia cina. Biosaintifika: J Biol Biol Edu 12:90-96

69. Herawati MM, Pudjihartati E, Kurnia TD, Setiawan AW (2020) The agronomic performance and artemisinin content of colchicne-induced polyploid genotypes Artemisia cina IOP Conf. Series: Mater Sci Eng $95915^{\text {th }}$ Joint Coference on Chemistry, Indonesia

70. Cara N, Piccoli PN, Bolcato L, Marfil CF, Mauelli RW (2020) Variation in the amino acids, volatile organic compounds and terpenes profiles in induced polyploids and in Solanum tuberosum varieties. Phytochem 180:112516

71. Gamborg OL, Miller RA, Ojima K (1968) Nutrient requirements of suspension cultures of soyabean root cells. Exp Cell Res 50:151-158

72. Murashige T, Skoog F (1962) A revised medium for rapid growth and bio assays with tobacco tissue cultures. Physiol Plant 15:473-495

73. Gao SL, Zhu DN, Cai ZH, Xu DR (1996) Autotetraploid plants from colchicine-treated bud culture of Salvia miltiorrhiza Bge. Plant Cell Tiss Org Cult 47:73-77

74. Heping H, Shanlin G, Lanlan C, Xiaoke J (2008) In vitro induction and identification of autotetraploids of Dioscorea zingiberensis. In Vitro Cell Dev Biol-Plant 44:448-455

75. Banyai W, Sangthong R, Karaket N, Inthima P, Mii M, Supaibulwatana K (2010) Overproduction of artemisinin in tetraploid Artemisia annua L. Plant Biotechnol 27:427-433

76. Kaensaksiri T, Soontornchainaksaeng P, Soonthornchareonnon N, Prathanturarug S (2010) Mutational breeding of Centella asiatica (L.) urban for medicinal purposes. Planta Med 76:P182

77. Majdi M, Karimzadeh G, Malboobi MA, Omidbaigi R, Mirzaghaderi G (2010) Induction of tetraploidy to feverfew (Tanacetum parthenium Schulz-Bip.): morphological, physiological, cytological, and phytochemical changes. HortSci 45:16-21

78. Sanwal SK, Rai N, Singh J, Buragohain J (2010) Antioxidant phytochemicals and gingerol content in diploid and tetraploid clones of ginger (Zingiber officinale roscoe). Sci Hortic 124:280-285

79. Touchell DH, Palmer IE, Ranney TG (2020) In vitro manipulation for crop improvement. Front Plant Sci 11:722

80. Eng WH, Ho WS (2019) Polyploidization using colchicine in horticultural plants: a review. Sci Hortic 246:604-617

81. Shahriari-Ahmadi F, Deghan E, Farsi M, Azizi M (2008) Tetraploid induction of Hyoscyamus muticus L. using colchicine treatment. Pak J Biol Sci 11:26532659.

82. Kumar S (2021) Impact of ploidy changes on secondary metabolites productions in plants. In: Srivastava AK, Kannaujiya VK, Singh RK, Singh D (eds) Evolutionary diversity as a source for anticancer molecules. Academic press, pp 29-46

\section{Publisher's Note}

Springer Nature remains neutral with regard to jurisdictional claims in published maps and institutional affiliations.

\section{Submit your manuscript to a SpringerOpen ${ }^{\circ}$ journal and benefit from:}

- Convenient online submission

- Rigorous peer review

- Open access: articles freely available online

- High visibility within the field

- Retaining the copyright to your article

Submit your next manuscript at $\boldsymbol{\nabla}$ springeropen.com 